\title{
Role Modeling in Medicine
}

\section{Sathiadas.MG}

"The example of the teacher is the most powerful influence upon the standards of conduct and practice of every trainee, whether medical student or junior doctor" GMC (1999)

Role modeling is described as teaching by example and influencing students in an unintentional, unaware, informal and episodic manner. Role modeling remains an elusive phenomenon in medical education, yet it is important to the professional development of students

Educating future doctors is one of the privileges and obligations of the medical profession. Doctors historically have followed and patterned their activities based on the practioners they respect and trust. These role models are admired for the way they act and for their professionalism, and whose behaviour is considered as a standard of excellence. They are the people in positions that we would like to reach, they possess qualities that we would like to have and they are people with whom we can identify ourselves. Both consciously and unconsciously we model our activities on such individuals.

Role modelling is a powerful teaching tool for passing on the knowledge, skills, and values of the medical profession, but its net effect on the behaviour of students is often negative rather than positive. Keng-Yin Loh (2010) identified the perception of the students and junior doctors on role model said more than half of the clinical teachers are poor role models. (2) The main deficiency was seen in the aspect of doctor- patient communication and relationship. The qualitative study published in this issue echoes the problems we face. Clearly this is a situation that should concern us and the institution in which we work.

Learning from role models occurs through observations and reflection, which is very complex as it involves conscious and unconscious activities.
By analyzing their own performance as role models, individuals can improve their personal performance.

Studies have shown, however, that with time medical students' cynicism increases and their humanitarianism decreases. Therefore, the development of appropriate attitudes in medical students is vital because it affects future practice, and it affects the doctor-patient relationship, the quality of care, and the outcome of health and illness. (3) The role modeling should also facilitate the process of socialisation into medical profession, helping to create a sense of identity of the students' current and future role. (6)

The desire to change our performance is the first step in improving role modelling. The areas that need to be addressed are personal level and at organisational level. Stratergies that can be adopted to change at the personal level are to demonstrate clinical competence, allocate protected time for teaching, show a positive attitude, implement a student-centred approach, facilitate reflection, encourage dialogue with colleagues, engage in staff development and work towards improving the institutional culture.

Role modeling is character formation of the medical student and as teachers we have both positive and negative aspects from which they learn hence role modeling is a powerful teaching strategy to mould the character of the learner.

"We must acknowledge that the most important, indeed the only, thing we have to offer our students is ourselves. Everything else they can read in a book." - D C Tosteson

\section{References:}

1. Cruess SR, Cruess RL, Steinert Y. Role modellingmaking the most of a powerful teaching strategy. BMJ : British Medical Journal. 2008;336(7646):718-721. doi:10.1136/bmj.39503.757847.BE. 
2. Wright SM, Kern DE, KolodnerK, Howard DM attributes of excellent attending physician role models. N Engl J Med 1998;7:1986-93

3. Schon DA. Educating the reflective practitioner: toward a new design for teaching and learning in the professions San Francisco: Jossey-Bass, 1987

4. Ambrozy, D.M., Irby, D.M., Bowen, J.L., Burack, J.H., Carline, J.D. and Stritter F.T. Role models perceptions of themselves and their influence on students' speciality choices. Acad Med 1997; 72 : 1119-21

5. Loh, K.-Y. and Nalliah, S. (2010), Learning professionalism by role-modelling. Medical Education, 44: 1123. doi:10.1111/j.13652923.2010.03827.x

6. Burgess, A., Oates, K. and Goulston, K. (2016), Role modelling in medical education: the importance of teaching skills. Clin Teach, 13: 134-137. doi:10.1111/tct.12397 